\title{
Aliphatic amine cured PDMS-epoxy interpenetrating network system for high performance engineering applications-Development and characterization
}

\author{
T V THANIKAI VELAN and I MOHAMMED BILAL* \\ Department of Chemistry, Crescent Engineering College, Chennai 600 048, India
}

MS received 1 December 1999; revised 24 July 2000

\begin{abstract}
A siliconized epoxy interpenetrating network (IPN) was synthesized from commercially available DGEBA epoxy resin GY250 (Ciba-Geigy, epoxy equivalent $=182-192$, viscosity $=9000-12000 \mathrm{cP}$ ) and hydroxyl terminated polydimethylsiloxane (PDMS). PDMS and GY250 were thoroughly mixed at $30^{\circ} \mathrm{C}$ to get the prepolymer. Stoichiometric amounts of PDMS-epoxy prepolymer, $\gamma$-aminopropyltriethoxysilane, aliphatic amine curing agent (HY951), and dibutyltindilaurate catalyst, were thoroughly mixed and cast in a mould after evacuating the entrapped air. The cured material was then taken out and post cured at $70^{\circ} \mathrm{C}$ for $10 \mathrm{~h}$. IPN was characterized by FTIR spectroscopy, SEM, DSC, TGA and viscosity measurements. Incorporation of PDMS in the epoxy matrix increased the viscosity and lowered the exotherm and pot-life. PDMS in IPN increased $T_{\mathrm{g}}$, heat-distortion temperature and reduced the percentage weight loss with increase in temperature. Incorporation of PDMS drastically reduced the tensile and flexural strengths and hardness. By reducing the tensile and flexural modulus, the siloxane moiety effectively reduced the internal stress of IPN thereby improving its impact strength and percentage elongation. PDMS increased the electric potential gradient of IPN to withstand without breakdown. An increase in the tracking index and arc resistance of IPN were observed, because of the presence of $\mathrm{Si}-\mathrm{O}-\mathrm{Si}$, which minimized the possibility of forming carbonized path. Volume and surface resistivities of IPN also increased with the incorporation of PDMS. The siliconized epoxy IPN, with better impact and thermal resistance, may be used in automobile and aerospace applications to withstand high temperature, and mechanical stress. The PDMS-epoxy IPN may be used for encapsulation, high temperature and high voltage application due to their low shrinkage and lesser internal stress. With the improved electrical characteristics, IPN may be used for high performance electrical insulation, insulator housings, and encapsulation to withstand high voltage, moisture, oxidation, chemical attack, biological attack, outdoor weathering, contamination, electrical, mechanical and thermal stress.
\end{abstract}

Keywords. PDMS; siloxane; epoxy; siliconized epoxy matrix; interpenetrating network.

\section{Introduction}

Any insulating material in service is exposed to moisture, oxidation, chemical attack, biological attack, outdoor weathering, contamination, electrical, mechanical and thermal stress. Polymers are better insulating materials for high performance applications in contaminated environments (Looms 1990). However, these materials also deteriorate due to multiple stresses encountered in service and aging. No single polymer or polymer blend has the necessary properties for an outdoor insulating material to provide the desired mechanical or electrical characteristics. Desired performance and service life over a diverse range of service conditions may be achieved by synthesizing materials with complex formulations.

Polymeric materials with good hydrophobicity and erosion resistance are preferred for better insulation applications.

\footnotetext{
*Author for correspondence
}

Materials having such properties usually lack good mechanical characteristics. They are not rigid and self-supporting and hence are modified to improve their mechanical characteristics for high performance applications (Bascom et al 1975; Mackevich and Shah 1997). Silicones, owing to their hydrophobicity (Gorur et al 1991; Looms 1990; Karady et al 1995) have been much widely used for outdoor insulation. The hydrophobicity is due to the presence of flexible $\mathrm{Si}-\mathrm{O}$ linkage and mobile silicone chains. Low surface energy of silicone imparts better hydrophobicity and hence silicones show very low leakage current in wet conditions even if contamination is present (Simmons et al 1997). Their mechanical properties do not vary much over a wide temperature range. However, they possess very poor mechanical characteristics. Epoxy resins possess good mechanical and electrical characteristics. However, they have comparatively less hydrophobicity and impact strength (Gutman et al 1997). They are often modified to improve their hydrophobicity, weathering characteristics and impact strength for 
high-tech applications (Sultan and Mc Garry 1973; Bascom et al 1975).

Polymer blends usually exhibit separate $T_{\mathrm{g}}$ values due to thermodynamic incompatibility. Siloxane is made to chemically bond with epoxy resin to form the interpenetrating network with desired characteristics and avoid phase separation (Nguyen and Suh 1984; Frisch 1985). Compounding the incompatible siloxane with epoxy resin is effective in achieving the desired characteristics, yet the method of compounding remains the state of the art. In this study, an attempt was made to synthesize and characterize a siliconized epoxy IPN, by cross-linking epoxy resin and hydroxyl-terminated polydimethylsiloxane (PDMS), using $\gamma$-aminopropyltriethoxysilane ( $\gamma$-APS) as cross-linking agent, dibutyltindilaurate (DBTDL) as catalyst, and an aliphatic amine (HY951, Ciba-Geigy) as curing agent (Serier et al 1991).

\section{Experimental}

Commercially available epoxy resins GY250 (DGEBA, Ciba-Geigy) having epoxy equivalent about 182-192 with viscosity $9000-12000 \mathrm{cP}$ was used in this study. The silicone component of interpenetrating network system was derived from octamethylcyclotetrasiloxane (WackerChemie, Germany). Octamethylcyclotetrasiloxane (OMCTS) and potassium hydroxide catalyst $(0.22 \%$ on the weight of OMCTS) were taken in a five-necked round-bottomed flask. The temperature of the mixture was gradually raised to $90^{\circ} \mathrm{C}$ over a period of $45 \mathrm{~min}$ and maintained at $90^{\circ} \mathrm{C} \pm 1^{\circ} \mathrm{C}$ for $4 \mathrm{~h}$, using thermostatically controlled oil bath and an inert atmosphere was maintained in the reaction medium by purging nitrogen. The reaction mixture was slowly cooled to about $50^{\circ} \mathrm{C}$ to avoid frothing. After degassing, the unreacted oligomer was removed by gradually increasing the temperature to $180^{\circ} \mathrm{C}$. Molecular weight of the polymer was evaluated from the viscosity of the PDMS, which was determined using Brookfield viscometer.

PDMS and DGEBA were thoroughly mixed at $30^{\circ} \mathrm{C}$ to get the prepolymer. The prepolymer was degassed before characterization. Viscosity of the prepolymer was measured using Brookfield viscometer and a FTIR spectrum was taken using Perkin-Elmer FTIR spectrometer.

Diethylenetriamine (HY951, Ciba-Geigy) with an amine equivalent $=20.6 \mathrm{eq} . / \mathrm{g}$ was used as the curing agent.

Table 1. Amount of curing agent, cross-linking agent and catalyst used in synthesis of siliconized epoxy system.

\begin{tabular}{lccc}
\hline Ratio of & $\begin{array}{c}\text { Amount of } \\
\text { curing agent } \\
\text { epoxy/PDMS }\end{array}$ & $\begin{array}{c}\text { Cross-linking } \\
\text { agent } \\
(g)\end{array}$ & $\begin{array}{c}\text { Catalyst } \\
(g)\end{array}$ \\
\hline $100 / 0$ & 10 & - & - \\
$90 / 10$ & 9 & $0 \cdot 2$ & $0 \cdot 10$ \\
$80 / 20$ & 8 & $0 \cdot 3$ & $0 \cdot 15$ \\
$70 / 30$ & 7 & $0 \cdot 4$ & $0 \cdot 20$ \\
\hline
\end{tabular}

Diethylenetriamine at 95 index of siliconized epoxy prepolymer, calculated amounts of silane adhesion promoter and dibutyltindilaurate catalyst, were added sequentially to the prepolymer blend (table 1). The resulting product was cast in a mould after evacuating the entrapped air. The cured material was then taken out and post cured at $70^{\circ} \mathrm{C}$ for $10 \mathrm{~h}$.

Heat distortion temperature was determined using S.C. Day Heat Distortion Temperature apparatus as per ASTM 648. Thermogravimetric analysis was carried out using TGA-Mettler TA3000. A differential scanning calorimeter (Dupont 2000) was used to measure the glass transition temperature $\left(T_{\mathrm{g}}\right)$ of a specimen. The measurements were carried out from $0^{\circ} \mathrm{C}$ to $350^{\circ} \mathrm{C}$, with a heating rate of $10^{\circ} \mathrm{C} / \mathrm{min}$ under nitrogen gas. The morphology of the samples was examined by scanning electron microscopy. Mechanical properties (tensile strength, tensile modulus, percentage elongation, flexural strength and flexural modulus) were studied using an Instron Model 8502 machine as per ASTM procedure. Impact strength was tested as per ASTM procedure (ASTM D256). Hardness of the specimen was tested using Durometer (Shore D) as per ASTM D2240.

Dielectric strength was determined by step by step test as per ASTM D149. Comparative tracking index was determined as per ASTM D3638 on the surface of a specimen. Volume and surface resistivities were determined as per ASTM D257 on the flat surface of a specimen. Arc resistance was measured as per ASTM D495.

\section{Results and discussion}

Molecular weight of PDMS synthesized from OMCTS was evaluated using viscosity values $\left(M_{\mathrm{n}}=1000 \mathrm{~g} / \mathrm{mol}\right.$, refractive index $=1.3985$, density $=0.97 \mathrm{~g} / \mathrm{cm}^{3}$, viscosity $100 \mathrm{cP}$ at $\left.25^{\circ} \mathrm{C}\right)$.

Prepolymer obtained by mixing PDMS and DGEBA was allowed to stand in a stability column for a period of 6 months at $30^{\circ} \mathrm{C}$, in order to assess its stability and homogeneity and to ascertain any chemical change during storage.

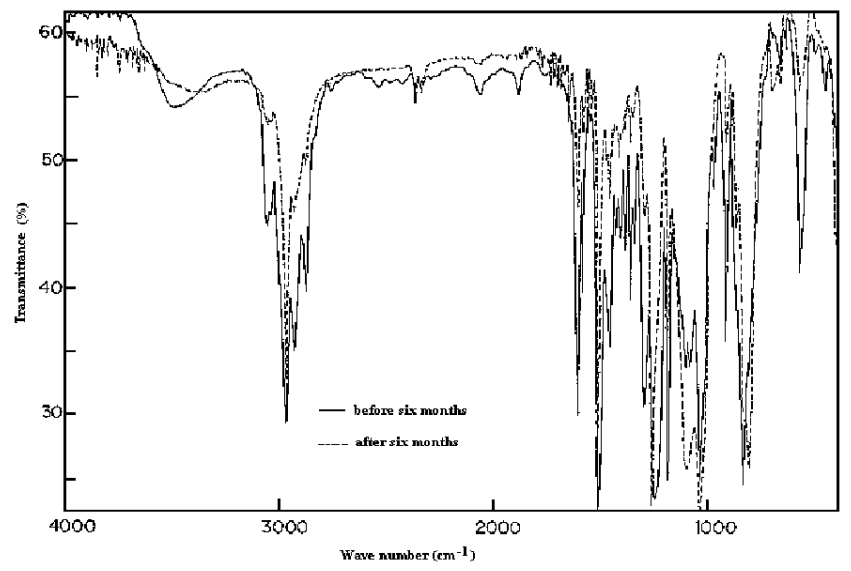

Figure 1. FTIR spectrum of siliconized epoxy prepolymer before and after six months ageing. 
Table 2. Properties of siliconized epoxy system.

\begin{tabular}{lllll}
\hline & \multicolumn{4}{c}{ Percentage PDMS } \\
\cline { 2 - 5 } Property & 0 & 10 & 20 & 30 \\
\hline Pot life $(\mathrm{min})$ & 40 & 35 & 28 & 23 \\
Exotherm $\left({ }^{\circ} \mathrm{C}\right)$ & 70 & 50 & 42 & 38 \\
Percentage weight loss (TGA) & $45 \cdot 03$ & $43 \cdot 65$ & $41 \cdot 25$ & $37 \cdot 00$ \\
$T_{\mathrm{g}}\left({ }^{\circ} \mathrm{C}\right)$ & $64 \cdot 1$ & $68 \cdot 8$ & $75 \cdot 1$ & $79 \cdot 2$ \\
HDT $\left({ }^{\circ} \mathrm{C}\right)$ & 85 & 88 & 91 & 93 \\
Dielectric strength $(\mathrm{V} / \mathrm{mm})$ & $11 \cdot 16$ & $18 \cdot 99$ & $20 \cdot 21$ & $21 \cdot 89$ \\
Comparative tracking index $(\mathrm{V})$ & 400 & 450 & 500 & 550 \\
Volume resistivity $\left.(\Omega \mathrm{cm})^{2}\right)$ & $3 \cdot 56 \times 10^{12}$ & $2 \cdot 16 \times 10^{14}$ & $>10^{14}$ & $>10^{14}$ \\
Surface resistivity $(\Omega \mathrm{cm})$ & $3 \cdot 8 \times 10^{9}$ & $5 \cdot 0 \times 10^{12}$ & $5 \cdot 8 \times 10^{13}$ & $6 \cdot 6 \times 10^{14}$ \\
Arc resistance $(\mathrm{sec})$ & 83 & 87 & 92 & 98 \\
Tensile strength $\left(\times 10^{6} \mathrm{~N} / \mathrm{m}^{2}\right)$ & $42 \cdot 45$ & $26 \cdot 09$ & $24 \cdot 62$ & $16 \cdot 22$ \\
Tensile modulus $\left(\times 10^{-3} \mathrm{~N} / \mathrm{m}^{2}\right)$ & $22 \cdot 33$ & $2 \cdot 37$ & $2 \cdot 21$ & $2 \cdot 16$ \\
Percentage elongation & $1 \cdot 35$ & $1 \cdot 92$ & $2 \cdot 11$ & $4 \cdot 72$ \\
Flexural strength $\left(\times 10^{6} \mathrm{~N} / \mathrm{m}^{2}\right)$ & $103 \cdot 38$ & $62 \cdot 67$ & $28 \cdot 70$ & $24 \cdot 73$ \\
Flexural modulus $\left(\times 10^{-3} \mathrm{~N} / \mathrm{m}^{2}\right)$ & $2 \cdot 48$ & $2 \cdot 43$ & $2 \cdot 01$ & $1 \cdot 30$ \\
Hardness $($ shore $\mathrm{D})$ & 86 & 79 & 73 & 68 \\
Impact strength $\left(\mathrm{kg} / \mathrm{cm}^{2} / \mathrm{cm}^{2}\right)$ & $5 \cdot 1$ & $8 \cdot 32$ & $14 \cdot 15$ & $20 \cdot 73$ \\
\hline
\end{tabular}

No appreciable change in viscosity or in the FTIR spectral ranges was observed which confirmed the stability of the prepolymer (figure 1 and table 2).

In the FTIR spectrum of the prepolymer (figure 2), absorption peaks at $1232 \mathrm{~cm}^{-1}$ and $831 \mathrm{~cm}^{-1}$ indicate the symmetrical stretching vibration and asymmetric stretching due to the presence of epoxy ring, respectively. These peaks are absent after the curing reaction, which confirms the opening of epoxide group (figure 3). The absorption peaks at $2969 \mathrm{~cm}^{-1}, 2830 \mathrm{~cm}^{-1}$ and $1385 \mathrm{~cm}^{-1}$ are due to the asymmetric methyl group stretching confirming the presence of $\mathrm{Si}-\mathrm{O}-\mathrm{CH}_{3}$ and $\mathrm{Si}-\left(\mathrm{CH}_{2}\right)_{3}$ groups (figures 2 and 3). Absence of peak at $3500 \mathrm{~cm}^{-1}$ for the $\mathrm{OH}$ stretching indicates the absence of free $\mathrm{OH}$ group of the hydroxyl terminated PDMS, which has taken part in the network formation (figure 3). However, the peak at $960 \mathrm{~cm}^{-1}$ confirms the presence of residual $\mathrm{Si}-\mathrm{OH}$ groups respectively. Absence of free $\mathrm{NH}_{2}$ group of the $\gamma$-APS is evident by the absence of $\mathrm{N}-\mathrm{H}$ stretching at $3300 \mathrm{~cm}^{-1}$. Scanning electron micrograph for the siliconized epoxy IPN with 10\% PDMS is given in figure 4.

Formation of siliconized epoxy IPN with $\gamma$-APS in the presence of DBTDL catalyst may be explained in two stages.

\section{Stage I:}

The first stage involves the reaction between the epoxide ring of the epoxy resin and amino group of the $\gamma$-APS.<smiles>CCOCC(CN(CCO)CCO)NCC(O)[C@@H]1CO1</smiles>

\section{Stage II:}

In the second stage, the reaction between epoxy and PDMS is promoted by the alkoxy group of $\gamma$-aminopropyltriethoxysilane. This compatibilizes the siloxane (10 parts w/w) with the DGEBA.

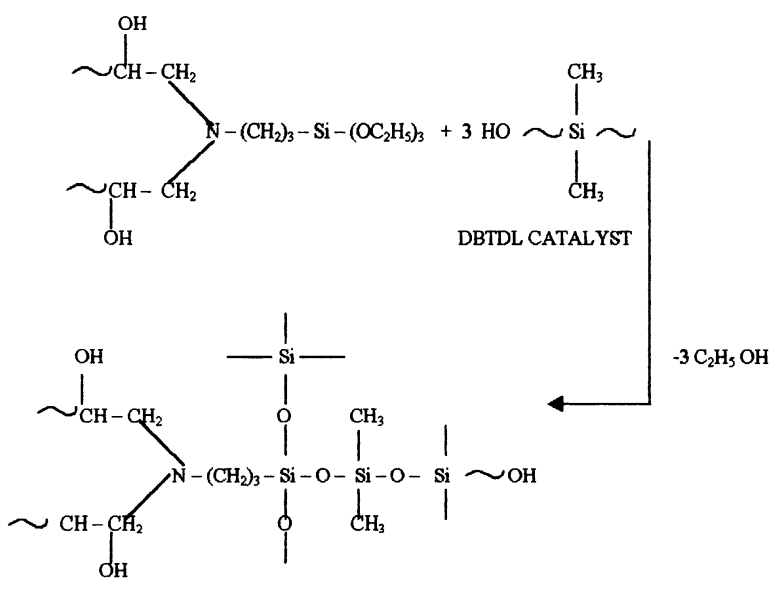

(A)

Reaction with curing agent:

The diamine-curing agent reacts with the major portion of the DGEBA and opens the ring of the epoxy group. The amino groups react with the hydroxyl group of the siloxane as well as the hydroxyl group formed in the resin during the ring opening reaction.

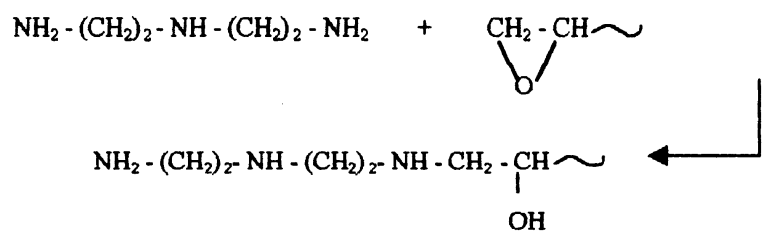

(B) 


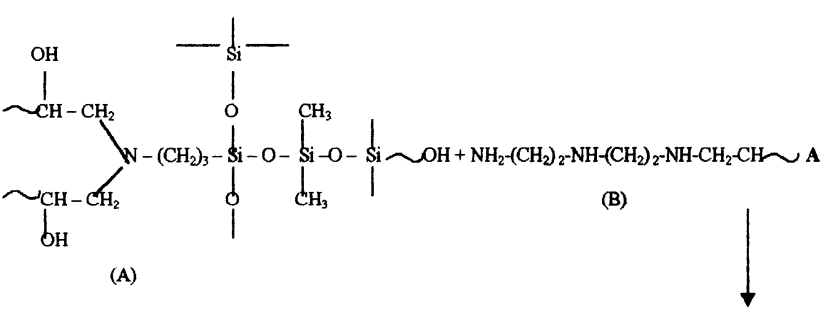<smiles>CCCCCCCCCCCCCCCCCCCC(C)O</smiles>

DSC curves for PDMS-IPN are given in figure 5. It is observed from the sharp peaks that IPN systems have single glass transition temperature $\left(T_{\mathrm{g}}\right)$. Incorporation of PDMS increased the $T_{\mathrm{g}}$, which further increased with additional increments of PDMS content in IPN. TGA data show that the PDMS-epoxy IPN decompose exothermally (table 2). The decomposition exotherm peaks around $350^{\circ} \mathrm{C}$. The decomposition of the cured resins begins at $300^{\circ} \mathrm{C}$ and follows the same pattern in all the cases. It is also observed that the decomposition temperature increased with increase in PDMS content (figure 5). The heat distortion temperature of IPN increased with increase in percentage PDMS (table 2). Percentage weight loss in the cured resin was lowered by increasing PDMS content.

Viscosity increased with increase in percentage PDMS in IPN (table 2). However, this lowered the exotherm and potlife. The decrease in exotherm and pot-life accounts for reduction in shrinkage and hence lowering the internal stress. Incorporation of PDMS drastically reduced the tensile and flexural strengths, and hardness. This is due to the elastomeric nature of PDMS, reduction in cross-linking density and lowering of internal stress by PDMS. This greatly influences the tensile and flexural modulus, percentage elongation and impact strength. The energy dissipating character of the

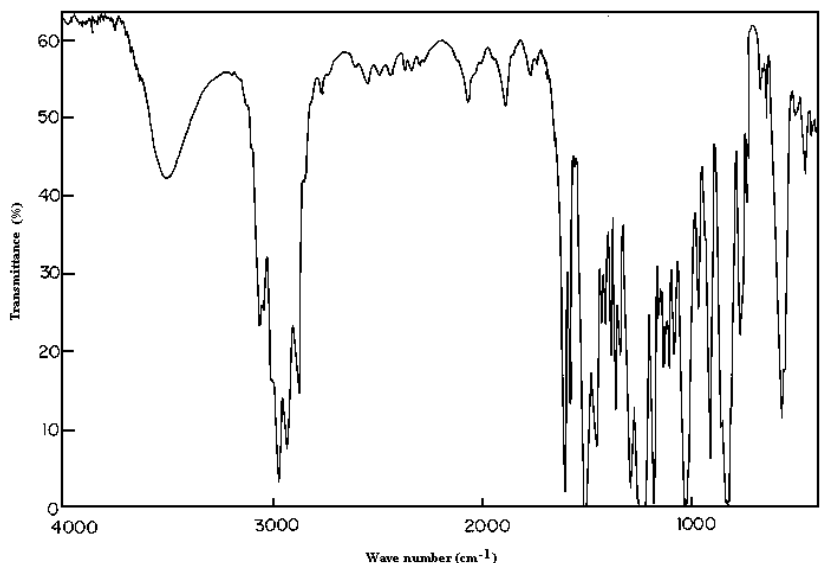

Figure 2. FTIR spectrum of siliconized epoxy prepolymer. siloxane moiety contributes mainly to the increase of impact strength, percentage elongation and decreases the tensile and flexural modulus. By reducing the tensile modulus, the siloxane moiety effectively reduces the internal stress of IPN (Sung and Lin 1997).

Dielectric strength is highly influenced by the presence of PDMS in IPN. PDMS increases the electric potential gradient of IPN to withstand without breakdown. The dielectric strength increases with an increase in percentage PDMS content in IPN. PDMS present in IPN increases the tracking index by reducing the possibility of forming carbonized path in the organic insulating material, when high voltage current is passed. Because of the presence of $\mathrm{Si}-\mathrm{O}-\mathrm{Si}$ linkage, there is a discontinuity in the carbon chain, which does not allow the formation of continuous carbonized path and reduces the leakage or fault path, across the surface of IPN (Simmons et al 1997) (table 2). Hence, the material may be used for electrical insulation with a reliable performance even in salty humid conditions (Sung and Lin 1997). From table 2, it is observed that the volume and surface resistivities of IPN also increase with the incorporation of PDMS. Arc resistance of IPN is improved by the incorporation of PDMS. Increase in PDMS content increases

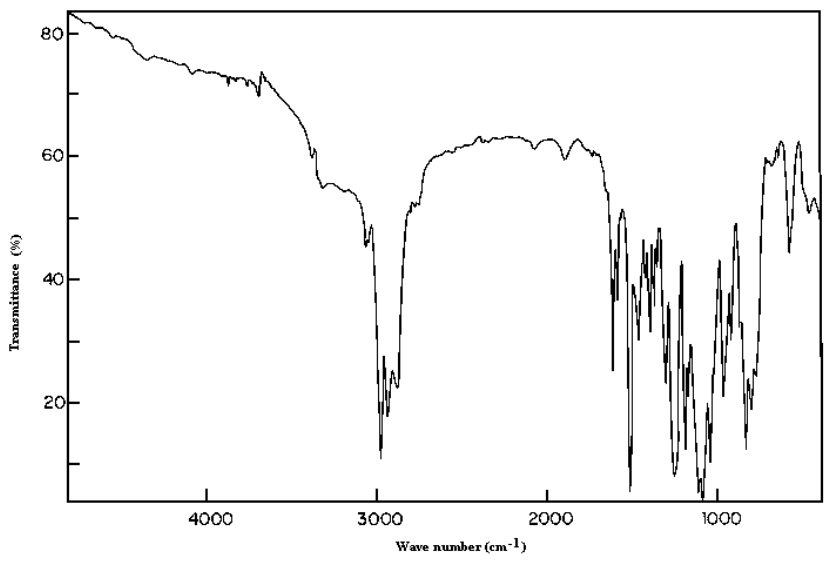

Figure 3. FTIR spectrum of cured siliconized epoxy (10/90) prepolymer.

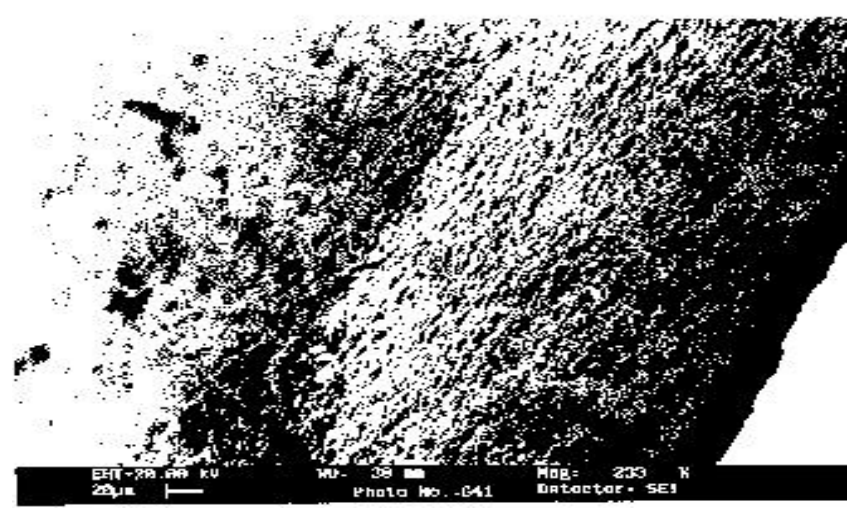

Figure 4. SEM photograph of PDMS-epoxy IPN. 


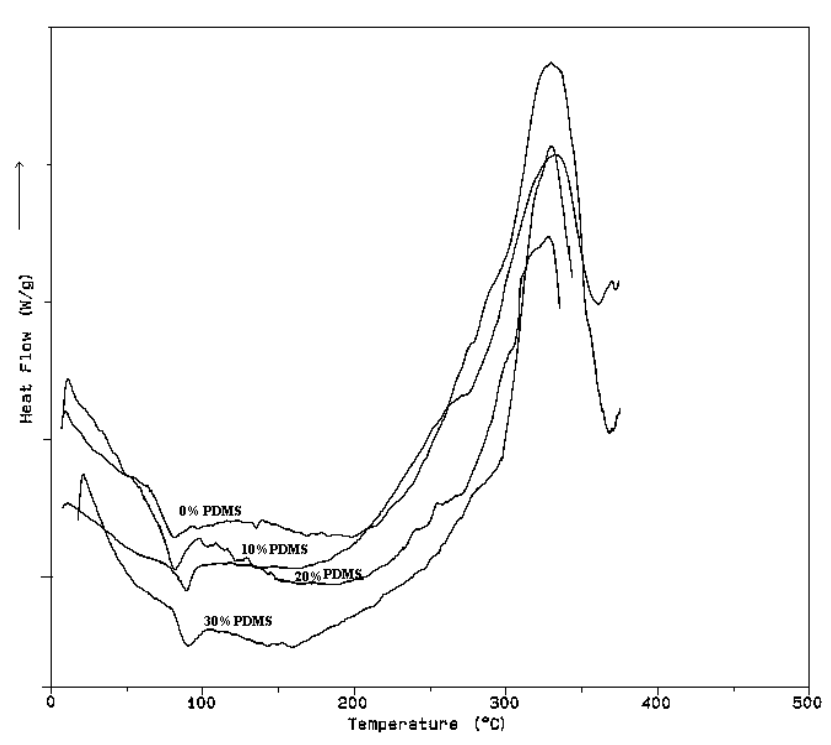

Figure 5. DSC curves of epoxy and PDMS-epoxy systems.

the ability of IPN to withstand the discharge of high voltage, low current arc across the surface without rendering it conductive. The discontinuity in the carbon chain due to the incorporation of siloxane units is responsible for improved arc resistance.

\section{Conclusion}

PDMS-epoxy interpenetrating network, synthesized from commercially available epoxy resin GY250 (Ciba-Geigy) and hydroxyl-terminated PDMS at room temperature using aliphatic amine curing agent HY951 (Ciba-Geigy) was used along with dibutyltindilaurate catalyst and $\gamma$-APS as cross-linking agent. IPN was characterized by FTIR, viscosity, thermal, mechanical and electrical stu- dies. IPN has better electrical and thermal characteristics with high impact resistance compared to the virgin epoxy system. The PDMS epoxy IPN may be used for encapsulation, high temperature and high voltage application due to their low shrinkage and lesser internal stress. It is suggested that IPN with better electrical and thermal characteristics with improved impact resistance may be used in high performance electrical insulation, encapsulation, insulator housings and aerospace applications to withstand high voltage, moisture, oxidation, chemical attack, biological attack, outdoor weathering, contamination, electrical, mechanical and thermal stress.

\section{References}

Bascom W D, Cottington R L, Jones R L and Peyser P 1975 J. Appl. Polym. Sci. 192425

Frisch H L 1985 Br. Polym. J. 17149

Gorur R, Johnson L and Hervig H 1991 IEEE Trans. Power Delivery 61361

Gutman I, Hartings R, Matsuoka R and Konda K 1997 IEEE Elect. Insul. Mag. 1336

Karady G G, Shah M and Brown R L 1995 IEEE Trans. Power Delivery 101965

Looms J S T 1990 Insulators for high voltage (London: Peter Peregrinus Ltd.) pp 17-19

Mackevich J and Shah M 1997 IEEE Elect. Insul. Mag. 135

Nguyen L T and Suh N P 1984 Rubber modified thermoset resins (eds) $\mathrm{C} \mathrm{K}$ Riew and $\mathrm{J} \mathrm{K}$ Gillham (Washington DC: Am. Chem. Soc.) Chap. 19

Serier A, Pascault J P and My L T 1991 J. Polym. Sci. Polym. Chem. Ed. 29209

Simmons S, Shah M, Mackevich J and Chang R J 1997 IEEE Elect. Insul. Mag. 1325

Sultan J N and Mc Garry F J 1973 J. Appl. Polym. Sci. 1329

Sung P H and Lin C Y 1997 Eur. Polym. J. 33903 